\title{
Pulmonary sarcoidosis with an alveolar radiographic pattern
}

\author{
JP BATTESTI, G SAUMON, D VALEYRE, J AMOUROUX, B PECHNICK, D SANDRON, \\ R GEORGES
}

From the Service de Pneumologie, Hôpital Avicenne, Bobigny, France, and the Groupe de Recherches $U$ 82, INSERM, CHU, Xavier-Bichat, Paris

ABSTRACT Thirty-three cases of sarcoidosis (4.4\% of 746 patients) showed an alveolar radiological pattern. A study of pulmonary function was carried out in 25 patients and compared with that of 46 patients with the interstitial radiological type of sarcoidosis. Twenty-two cases have been followed up from one to six years after the initial examination. The radiographic lesions were most often bilateral and included nodules greater than $15 \mathrm{~mm}$ with ill-defined margins or diffuse, infiltrative, non-retractile opacities with fluffy margins. Bilateral mediastinal lymph nodes were present in 27 patients. In 20 patients an associated reticulation was found on radiography. In four patients an open lung biopsy was done. The granulomatous nodules were identical to those found in other forms of sarcoidosis, although they were more confluent in the affected areas. Clinical and functional findings did not differ from those in the more common forms of sarcoidosis. Alveolar sarcoidosis has a sudden course. The alveolar radiological patterns always disappeared, with or without steroid treatment, while reticular patterns persisted in four patients. Rapid radiological changes were observed. Some functional abnormalities persisted in cases that were followed. It is concluded that alveolar sarcoidosis is a distinct acute form of sarcoidosis.

Sarcoid granulomas are found in the alveolar septa and less frequently in the walls of bronchi, pulmonary arteries, and veins. ${ }^{1}$ The radiological findings in pulmonary sarcoidosis may typically be of one of three types of diffuse interstitial opacities ${ }^{2}$ : reticular, reticulomicronodular, or nodular (nodules less than $5 \mathrm{~mm}$ in diameter). Less frequently the radiological pattern is called "alveolar."2 The aim of the work reported here was to determine whether sarcoidosis with the alveolar radiological pattern is a distinct type of sarcoidosis.

\section{Methods}

Seven hundred and forty-six patients with pulmonary sarcoidosis were studied. The radiological criteria for alveolar manifestations were those of Felson ${ }^{2}$ : opacities of the infiltrative type, nonretractile, with ill-defined margins and sometimes an air bronchogram, or nodules with ill-defined limits and diameters greater than $15 \mathrm{~mm}$. Thirty-three patients $(4.4 \%)$ satisfied those criteria. A study of pulmonary function was carried out in 25 of the 33

Address for reprint requests: Professor JP Battesti, Hôpitál Avicenne, 93009 Bobigny, France. patients and the results were compared with those of 46 patients with the more usual interstitial radiological pattern.

The pulmonary volumes and the forced expiratory volume during the first second $\left(\mathrm{FEV}, \mathrm{V}_{1}\right)$ were measured by spirometry. The functional residual capacity was measured by multiple-breath helium dilution. The standard values used were those of the European Communities. ${ }^{3}$ The transfer factor was evaluated by the single-breath carbon monoxide test (TLCO). ${ }^{4}$ The standards used have been published. ${ }^{5}$ The TLCO was scaled according to age and height (indicated as TLCO $\mathrm{Ht}$ ).

The static ventilatory mechanics were estimated through the relation between the volume measured at the mouth and the transpulmonary pressure during slow expiration. The following indices were calculated: static expiratory compliance (CL) measured at tidal volume, elastic recoil at total lung capacity (PI max), and coefficient of retraction (CR). ${ }^{6}$ The following standards were used: Yernault et $a l^{7}$ for CL/TLC and values obtained by Turner $e t$ $a^{8}$ for CR. The measurements of arterial oxygen tension $\left(\mathrm{PaO}_{2}\right)$ were made on blood obtained from the brachial artery. 
Lung function was measured at rest in the sitting position. All data are presented as means and standard errors of the mean unless otherwise noted.

\section{Results}

\section{CLINICAL FINDINGS}

Of the 33 patients studied, 23 were men and 10 women. The mean age was $28.4 \pm 1.85$ years. One patient was under 20 years; 30 were $20-40$ years; and 2 were over 40 . There were 26 white and seven black patients (including two Africans and one North African).

In 21 patients $(63.5 \%)$ the discovery of the radiological patterns had been made after syster atic examination. Respiratory symptoms were not present in these patients. In 12 patients $(36.5 \%)$ radiography was prompted by respiratory symptoms (cough, breathlessness during exertion, chest pain). In nine patients an $x$-ray examination had been done a year before; the appearances were normal in seven cases and showed enlarged hilar nodes in two cases. The clinical examination of the thorax gave negative results in all but one patient, in whom crackles were noted. Clinically, extrathoracic sarcoidosis was found in 13 patients; the lymph nodes were affected in nine, the skin in one, the parotid glands in one, the liver in two.

\section{RADIOLOGICAL FINDINGS}

The opacities of the alveolar type were usually bilateral and present in several zones. In 17 patients there were large nodules with ill-defined margins (fig 1), while 16 patients had diffuse infiltrative opacities, sometimes with an air bronchogram (fig 2 ). Spread to the middle and peripheral zones of the lung was the most frequent finding. The lesions extended to the costophrenic angle in only two patients, of whom one showed a pleural reaction. The presence of a clear zone inside the nodules was observed in six of the 10 patients in whom tomograms were performed. Bilateral mediastinal lymph nodes were present in 27 patients.

In 20 patients in addition to the alveolar patterns a reticular or reticulomicronodular pattern was observed. The patients showing only alveolar patterns constitute group A, while those showing alveolar and reticular patterns form group $B$.

\section{PULMONARY FUNCTION}

In 25 of the 33 patients respiratory function was studied when the diagnosis of sarcoidosis was made. The pulmonary function of 46 patients with an isolated interstitial radiological pattern was compared (group C) with that of the patients of group A and $B$. The age and sex of the patients studied, their

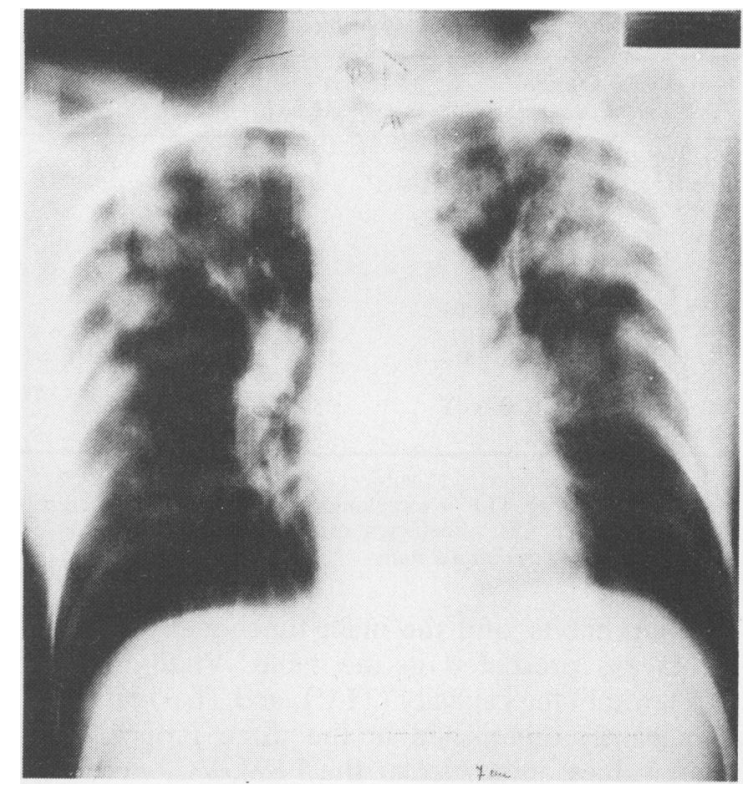

Fig 1 Chest tomogram showing large nodules with ill-defined margins and bilateral mediastinal lymph nodes.

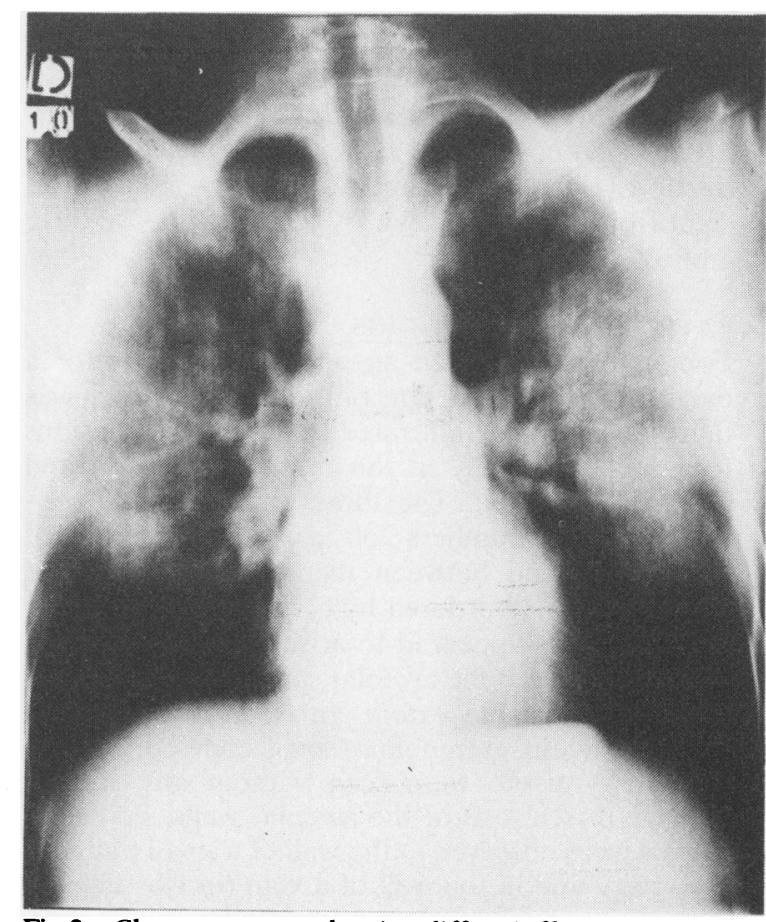

Fig 2 Chest tomogram showing diffuse infiltrative opacities with air bronchograms and bilateral mediastinal lymph nodes. 
Characteristics of patients and pulmonary function data

\begin{tabular}{|c|c|c|c|}
\hline $\begin{array}{l}\text { Patient group: } \\
\text { Radiological pattern: }\end{array}$ & $\begin{array}{l}\text { A } \\
\text { Alveolar }\end{array}$ & $\begin{array}{l}\text { B } \\
\text { Alveolar with fine reticulation }\end{array}$ & $\begin{array}{l}\text { C } \\
\text { Reticulonodular }\end{array}$ \\
\hline $\begin{array}{l}\text { No. of cases } \\
\text { Age (years) } \\
\text { Sex: M/F } \\
\text { Smoking: No/Yes } \\
\text { VC (\% of predicted) } \\
\text { TLC (\% of predicted) } \\
\text { FEV } / \mathrm{VC}(\% \text { of predicted) } \\
\text { RV/TLC (\% of predicted) } \\
\text { CL/TLC (\% of predicted) } \\
\left.\text { CR (kPa/dm }{ }^{3}\right) \\
\text { TLCO Ht (\% of predicted) } \\
\text { PaO2 (mm Hg) }\end{array}$ & $\begin{array}{l}11 \\
27 \\
9 / 2 \\
9 / 2 \\
80.6 \\
80.5 \pm 6.3 \mathrm{p}<0.01 \\
85 \cdot 3 \pm 5 \mathrm{p}<0.05 \\
96 \cdot 1 \pm 4.3 \mathrm{~N} \mathrm{~S} \\
114 \pm 7.1 \mathrm{NS} \\
103 \quad \pm 6 * \mathrm{~N} \mathrm{~S} \\
3.8 \pm 0.3 \dagger \mathrm{N} \mathrm{S} \\
84.3 \pm 8 \cdot 1 \mathrm{p}<0.05 \\
88 \pm 2.9 \mathrm{~N} \mathrm{~S}\end{array}$ & $\begin{array}{l}14 \\
30 \pm 3 \cdot 1 \\
8 / 6 \\
11 / 3 \\
82 \cdot 1 \pm 5 \cdot 1 \mathrm{p}<0.01 \\
82 \cdot 3 \pm 4 \cdot 4 \mathrm{p}<0.01 \\
102 \cdot 3 \pm 2 \cdot 8 \mathrm{~N} \mathrm{~S} \\
101 \cdot 9 \pm 6 \cdot 4 \mathrm{~N} \mathrm{~S} \\
90 \pm 8 \ddagger \mathrm{N} \mathrm{S} \\
7 \cdot 5 \pm 0.78 \mathrm{~N} \mathrm{~S} \\
71 \pm 5 \cdot 9 \mathrm{p}<0.01 \\
83 \pm 4.9 \mathrm{~N} \mathrm{~S}\end{array}$ & $\begin{array}{l}46 \\
30 \pm 1 \\
24 / 22 \\
35 / 11 \\
81 \pm 2.7 \mathrm{p}<0.01 \\
84.6 \pm 2.3 \mathrm{p}<0.05 \\
102 \pm 1.5 \mathrm{~N} \mathrm{~S} \\
107 \pm 3.3 \mathrm{~N} \mathrm{~S} \\
107 \pm 0.59 \mathrm{~N} \mathrm{~S} \\
5.8 \pm 0.39 \mathrm{~N} \mathrm{~S} \\
70.5 \pm 2.5 \mathrm{p}<0.01 \\
87 \pm 1.3^{* *} \mathrm{~N} \mathrm{~S}\end{array}$ \\
\hline
\end{tabular}

${ }^{*} 7$ subjects; $\nmid 8$ subjects; $¥ 11$ subjects; $\$ 8$ subjects; ||12 subjects; $\uparrow 43$ subjects; ${ }^{* *} 42$ subjects.

$\mathrm{VC}=$ vital capacity; $\mathrm{TLC}=$ total lung capacity $; \mathrm{FEV} \mathrm{V}_{1}=$ forced expiratory volume in one second $\mathrm{RV}=$ residual volume; $\mathrm{CL}=\mathrm{expiratory}$ static compliance; $\mathrm{CR}=$ coefficient of retraction; $\mathrm{TLCO}=$ transfer factor; $\mathrm{PaO}_{2}=$ arterial oxygen tension.

Conversion: SI to traditional units $-1 \mathrm{kPa}=7.5 \mathrm{~mm} \mathrm{Hg}$.

smoking habits, and the main functional measurements are presented in the table. Vital capacity (VC), total lung capacity (TLC), and TLCO Ht were significantly diminished in the three groups. The other values, in particular the $\mathrm{FEV}_{\mathrm{l}} / \mathrm{VC}$, were not significantly changed. Nevertheless, when each case was studied an obstructive syndrome $\left(\mathrm{FEV}_{1} / \mathrm{VC} \leqslant\right.$ $90 \%$ predicted value) was observed in five of 11 cases in group $\mathrm{A}$, two of 14 cases in group B, and five of 46 cases in group C. Transfer factor impairment was frequent: TLCO $\mathrm{Ht} \leqslant$ predicted value $-2 \mathrm{SD}$ in five out of 11 cases in group $A$, nine out of 14 cases in group B, and fifteen out of 46 cases in group $C$. There were significant differences between groups $A$ and $B$ in the coefficient of retraction (eight from group $A$ : mean $=3.8 \pm 0.3$; eight from group B: mean $=7.5 \pm 0.7, p<0.001$; group C: $5 \cdot 8 \pm 0 \cdot 3$ ).

\section{PATHOLOGICAL FINDINGS}

Four patients required an open lung biopsy for a diagnosis to be made. One of the samples, which was done outside the infiltrated zone, showed lesions localised exclusively in the bronchial mucosa and peribronchial area. The three other samples contained large numbers of confluent masses of granulomas and between them rare bronchial or alveolar spaces bordered by a cuboidal epithelium. These follicles appeared to arise in the interstitium but protrude into the alveolar spaces, thus occluding them to a variable extent. In two cases, between large confluent granulomas small zones of normal pulmonary tissue were seen without any specific damage or sclerosis of the alveolar walls. Follicular lesions were observed in the wall of a small pulmonary artery and in the wall of a vein (in two cases).

\section{NATURAL HISTORY}

The course of the disease was followed radiologi- cally in 22 patients. In 15 of them impaired respiratory function required steroid treatment for two years. The alveolar type patterns disappeared in all 15 and did not reappear for one year after the end of the treatment. On the other hand, the reticular patterns observed in 10 of the 15 are still present in three. Six of seven untreated patients (five in group A, one in group B) showed clearing of the radiological abnormality after three to nine months. In one the alveolar and reticular patterns are still present after 17 months, treatment being contraindicated. A rapid change in radiological appearance was seen often in a matter of few weeks. Changes of respiratory function could be followed in only 10 patients, for periods varying from one to six years. A significant improvement of TLC and VC was observed (TLC \% of predicted: mean increase = $13.5 \%, t=2 \cdot 34, \mathrm{p}<0.05 ; \mathrm{VC} \%$ of predicted: mean increase $11 \%, t=2.54, \mathrm{p}<0.05)$. The other values did not change significantly.

\section{Discussion}

There is a difference, according to most recent publications, in the frequency of the radiological alveolar pattern found in sarcoidosis. Considering only the nodular pseudotumoral forms, Romer ${ }^{9}$ estimated it to be $1 \%$, while Kirks ${ }^{10}$ found it in $2 \%$ and Sharma ${ }^{11}$ in $4 \%$ of their subjects with sarcoidosis. Shigematsu, ${ }^{12}$ considering all the alveolar patterns of sarcoidosis, estimated the frequency of this form to be $20 \%$. Felson ${ }^{2}$ thought that sarcoidosis was the most important cause of disseminated chronic alveolar opacities. In our study the alveolar forms occurred in $4.4 \%$ of patients with the disease.

Whether this radiological pattern, as Shigematsu suggested, ${ }^{12}$ is related to a particular form of sarcoidosis requires correlation studies between the radiological and the pathological data. Unfortu- 
nately such studies are rare and are interpreted differently. According to Sahn, ${ }^{13}$ the alveoli are invaded by mononuclear cells, which represent a non-specific reaction to the sarcoid granuloma present in the pulmonary interstitium. According to Shigematsu ${ }^{12}$ the alveoli contain epithelioid cells whose origin - endoalveolar or interstitial-is uncertain. According to Felson ${ }^{2}$ and Reed, ${ }^{14}$ the alveoli are compressed or filled with coalescent interstitial nodules.

The pathological observations made on lung biopsy specimens in four of our patients indicate that the granulomas are identical to those found in the common forms of the disease, but less diffuse and more confluent. Thus the radiological aspect of alveolar sarcoidosis appears to be due not to histological disorders of the alveoli but rather to the collapse of the alveolar walls by the confluence of interstitial granulomas. The cause of cavitation observed in some cases of alveolar sarcoidosis is unknown. ${ }^{15}$ Ischaemic or eosinophilic necrosis of conglomerate granulomas has been suggested. ${ }^{16}$ Nodules with cavitation were not observed in our biopsy specimens. The fact that in two cases we observed small zones of normal pulmonary tissue between large confluent granulomas suggests that the clear zones observed in the nodules' centres might correspond to undamaged parenchyma, surrounded by coalescent granulomas. ${ }^{15}$ The air bronchogram can occur in interstitial diseases such as sarcoidosis in this alveolar variety. ${ }^{14}$

Clinically, alveolar sarcoidosis seems to be an acute form, to judge by the young age of the patients, the presence of mediastinal nodes, and the frequent occurrence of a normal radiograph during the previous year. But the clinical findings are similar to those of the other acute forms of sarcoidosis. Likewise, the abnormalities of pulmonary function observed in the present group of patients did not differ from those observed in other patients with different radiographic patterns. ${ }^{17}{ }^{18}$ The combination of reticulation with the alveolar-type patterns should be taken into consideration. This radiological feature is most probably due to the extension of the granulomatous process into the interstitial tissue. In these cases we have observed more severe impairment of the coefficient of retraction. This can be explained by the association of diffuse interstitial lesions and lung shrinkage. ${ }^{19}$

The course of the disease was characterised by the improvement of the alveolar pattern either spontaneously or with corticosteroid treatment. Interstitial patterns can, however, persist even with treatment. Spontaneous radiographic clearing (six out of seven patients) was more frequently observed with the alveolar pattern than with other forms of acute sarcoidosis. $^{20}$

Rapid changes of radiological patterns are characteristic of alveolar sarcoidosis. ${ }^{2122}$ The pathological findings cannot explain this. In fact, it is hard to conceive that confluent granulomas seen in the biopsy specimens, which seem to cause the radiological pattern, can improve spontaneously so rapidly. Although the radiological patterns disappear, more often the functional measurements do not change when they are already abnormal at the first examination. Indeed, even though the pulmonary volumes did in some cases improve, compliance and the result of the single-breath carbon monoxide test did not change, at least during the period of observation. Similar observations concerning pulmonary volumes have been made by Onal $e$ al $^{23}$ in cases of nodular pulmonary sarcoidosis with radiographic resolution.

\section{References}

' Crystal RG. Pulmonary sarcoidosis: a disease characterised and perpetuated by activated lung T lymphocytes. Ann Int Med 1981;94:73-94.

${ }^{2}$ Felson B. Chest roentgenology. Philadelphia: Saunders, 1973.

${ }^{3}$ Aide mémoire pour la pratique de l'examen de la fonction ventilatoire par la spirographie. Luxembourg: Service des Publications des Communautés Européennes, 1961.

${ }^{4}$ Ogilvie CM, Forster RE, Blakemore WS, Morton JW. A standarised breath holding technique for the clinical measurement of the diffusing capacity of the lung for carbon monoxide. J Clin Invest 1957;36:1-17.

${ }^{5}$ Georges R, Saumon G, Loiseau A. The relationship of age to pulmonary membrane conductance and capillary blood volume. Am Rev Respir Dis 1978;117:1069-78.

- Schlueter DP, Immekus J, Stead WW. Relationship between maximal inspiratory pressure and total lung capacity (coefficient of retraction) in normal subjects and in patients with emphysema, asthma and diffuse pulmonary infiltration. Am Rev Respir Dis 1967;96:656-65.

${ }^{7}$ Yernault JC, Baran D, Englert M. Effect of growth and aging on the static mechanical lung properties. Bull Europ Physiopath Resp 1977;13:777-88.

${ }^{8}$ Turner JM, Mead J, Wohl ME. Elasticity of human lungs in relation to age. J Appl Physiol 1968;25:664-71.

${ }^{9}$ Romer EK. Sarcoidosis with large nodular lesions simulating pulmonary metastases. Scand J Respir Dis 1977;58:11-6.

${ }^{10}$ Kirks DR, McCormick VD, Greenspan RH. Pulmonary sarcoidosis. Roentgenologic analysis of 150 patients. Am J Roentgenol 1973;117:777-86.

"Sharma OP, Hewlett R, Gordonson J. Nodular sarcoidosis: an unusual radiographic appearance. Chest 1973;64:189-92.

${ }^{12}$ Shigematsu N, Emori K, Matsuba K. Clinicopathologic characteristics of pulmonary acinar sarcoidosis. Chest 1978;73:1868.

${ }^{13}$ Sahn SA, Schwarz MI, Lakshminarayan S. Sarcoidosis. The significance of an acinar pattern on chest roentgenogram. Chest 1974;65:684-7.

${ }^{14}$ Reed JC, Madewell JE. The air bronchogram in interstitial disease of the lung. Radiology 1975;116:1-9.

is Tellis MCJ, Putnam JS. Cavitation in large multinodular pulmonary disease. Chest 1977;71:792-3.

${ }^{16}$ Rohatgi PK, Schwab LE. Primary acute pulmonary cavitation in sarcoidosis. Am J Radiol 1980;134:1199-203. 
${ }^{17}$ Basset G, Georges R, Turiaf J. Anomalies des échanges alvéolocapillaires et de la compliance dans la sarcoidose médiastinopulmonaire. In: Turiaf J, Chabot J, eds. La sarcoïdoserapport de la IVème conférence internationale. Paris: Masson, 1967:436-54.

18 Saumon G, Georges R, Loiseau A, Turiaf J. Membrane diffusing capacity and pulmonary capillary blood volume in pulmonary sarcoidosis. Ann N Y Acad Sci 1976;278:284-91.

19 Gibson GJ, Pride NB. Pulmonary mechanics in fibrosing alveolitis. The effects of lung shrinkage. Am Rev Respir Dis 1977;116:637-47.
${ }^{20}$ Turiaf J, Johns CJ, Terstein AS, Tsuji S, Wurm K. The problem of the treatment of sarcoidosis: report of the subcommittee on therapy. Ann N Y Acad Sci 1976;278:743-51.

${ }^{21}$ Heitzman ER. The lung: Radiologic pathologic correlation. Saint Louis: Mosby, 1973:264-5.

${ }^{22}$ Felson B. Uncommon roentgen patterns of pulmonary sarcoidosis. Dis Chest 1958;34:357-67.

${ }^{23}$ Onal E, Lopata M, Lourenco RV. Nodular pulmonary sarcoidosis. Clinical, roentgenographic and physiologic course in five patients. Chest 1977;72:296-300. 